\title{
La etnohistoria en México
}

\author{
Juan Manuel Pérez Zevallos
}

$\mathrm{L}$

OS ARTíCULOS del presente número de Desacatos tienen como fin proporcionar al lector las reflexiones sobre la práctica de la etnohistoria y buscan mostrar su desarrollo con el objetivo de ofrecer planteamientos novedosos que puedan servir para futuras investigaciones y la controversia. ${ }^{1}$

De ser considerada la etnohistoria, en sus inicios, como una metodología, se transformó en una disciplina cuyos resultados han tenido aceptación por los científicos sociales. Como disciplina se dedica al estudio de sociedades que sufrieron dominación colonial, para su práctica se ha nutrido tanto de la historia como de la antropología,

\section{JUAN MANUEL PÉREZ ZEVALLOS: CIESAS.}

${ }^{1}$ El origen de la etnohistoria como disciplina ha sido discutido desde distintas perspectivas. En la compilación, La etnohistoria en Mesoamérica y los Andes ("Textos básicos y manuales", Instituto Nacional de Antropología e Historia, México, 1987), se reunieron los artículos de conocidos investigadores del área andina y mesoamericana y dieron una idea de las preocupaciones que había entre 1962 y 1982. Los trabajos ahí reunidos son los de Pedro Carrasco, "Sobre la etnohistoria en Mesoamérica" "La antropología y la investigación histórica: el estudio del indio" y "La etnohistoria en Mesoamérica"; de Carlos Martínez Marín, "La etnohistoria: un intento de explicación"; la réplica que hizo Carlos García-Mora bajo el título de "La etnohistoria y la unidad de la antropología”; los de John V. Murra, "Temas de estructura social y económica en la etnohistoria y el antiguo folklore andino", "Las investigaciones en etnohistoria andina y sus posibilidades en el futuro" " "La etnohistoria"; los de Franklin Pease, "Etnohistoria andina: un estado de la cuestión" y "Etnohistoria andina: problemas de fuentes y metodología"; y la crítica a la etnohistoria andina de Luis Millones, "Etnohistoriadores y etnohistoria andina: una tarea difícil, una disciplina heterodoxa". en aquella unión reside su riqueza y la atracción que ejerce sobre los investigadores, pero también es un campo difícil de definir, difuso y sin límites precisos, como apuntó don Gonzalo Aguirre Beltrán, hace ya varios años, "según podrá advertirse las fronteras de la etnohistoria no son fáciles de fijar; probablemente nunca lo llegarán a ser".

El contenido de los trabajos lo podemos repartir en tres grandes vertientes que dan muestra del desarrollo de una disciplina como la etnohistoria.

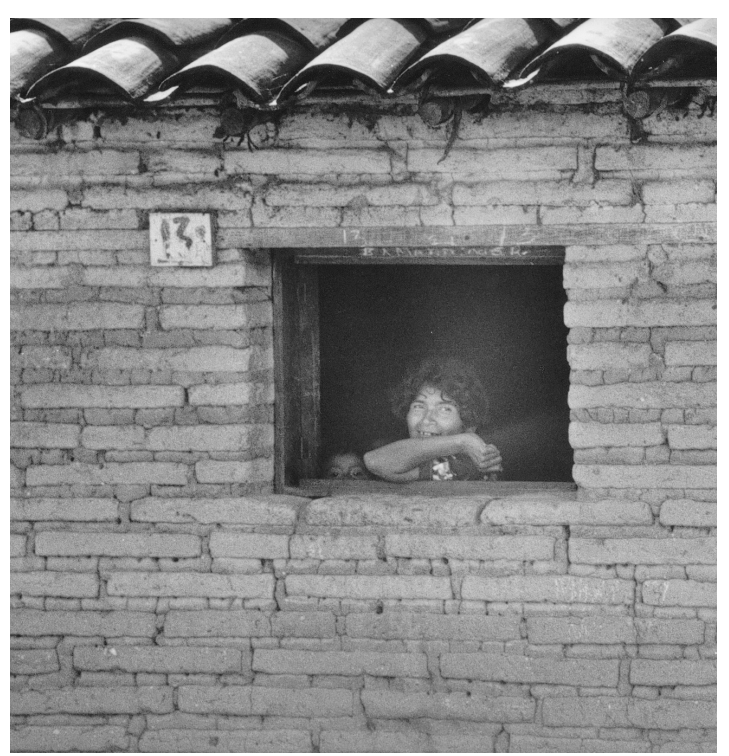

San Miguel Panixtlahuaca, chatina, Vittorio D’Onofri, 1995 
La primera tiene que ver con el diálogo entre historiadores y antropólogos. Al ser la etnohistoria una lectura antropológica de la documentación histórica, ésta se convirtió en práctica y estilo de trabajo que obligó a que muchos historiadores rompieran el conservadurismo que tenían sobre el uso de teorías o conceptos antropológicos, y a los antropólogos a ver con mayor rigor el uso de las fuentes documentales. Desde esta perspectiva, los análisis realizados por antropólogos e historiadores están en proceso de convergencia, pues podemos observar que muchos trabajos antropológicos incorporan la dimensión histórica y los de historia tienen progresivamente un carácter más antropológico. El resultado de esta relación ha abierto nuevos caminos y perspectivas de futuros trabajos. Sin embargo, hay que tomar en cuenta lo que nos recuerda Romero Frizzi: no se trata de que "sigamos repitiendo que etnohistoria es la antropología aplicada al pasado", se trata de que reflexionemos sobre "qué implica exactamente esta combinación". ${ }^{2}$

El antrópologo Bernard S. Cohn, ${ }^{3}$ si bien redactó su contribución en 1962, reflexiona sobre el acercamiento que tuvo con historiadores, abunda en la naturaleza de la historia y la antropología y en la práctica de los profesionales, "moldeada por el proceso de investigación en los dos campos", a partir de su experiencia señala que la colaboración entre historiadores y antropólogos había entrado en una "fase nativista" y se había vuelto "un tanto gélida”. Por fortuna, esta situación no priva hoy en día, los "falsos estereotipos" sugeridos en el artículo de Cohn han sido superados, las investigaciones etnohistóricas muestran que el diálogo entre historiadores y antropólogos ha sido fructífero, como lo sugieren María de los Ángeles Romero Frizzi y Frank Salomon. ${ }^{4}$ Aunque es

2 Romero Frizzi, “La historia es una”, en este número. Mario Ruz (1994) también hizo esta observación: "lugar común es invocar aquella manoseada explicación de que la etnohistoria estudia fenómenos históricos con los métodos de la antropología, aunque nadie nos revela el secreto de cómo aplicar los métodos de una disciplina soslayando las premisas teóricas que les dieron razón de ser". "La etnohistoria en México: el reto de una visión antropológica global”, Revista Mexicana de Estudios Antropológicos, XL, pp. 181-186.

3 Bernard S. Cohn, "Un antropólogo...", en este número.

${ }^{4}$ María de los Ángeles Romero Frizzi, "La historia es una”, y de Frank Salomon, “Una etnohistoria...", en este número.

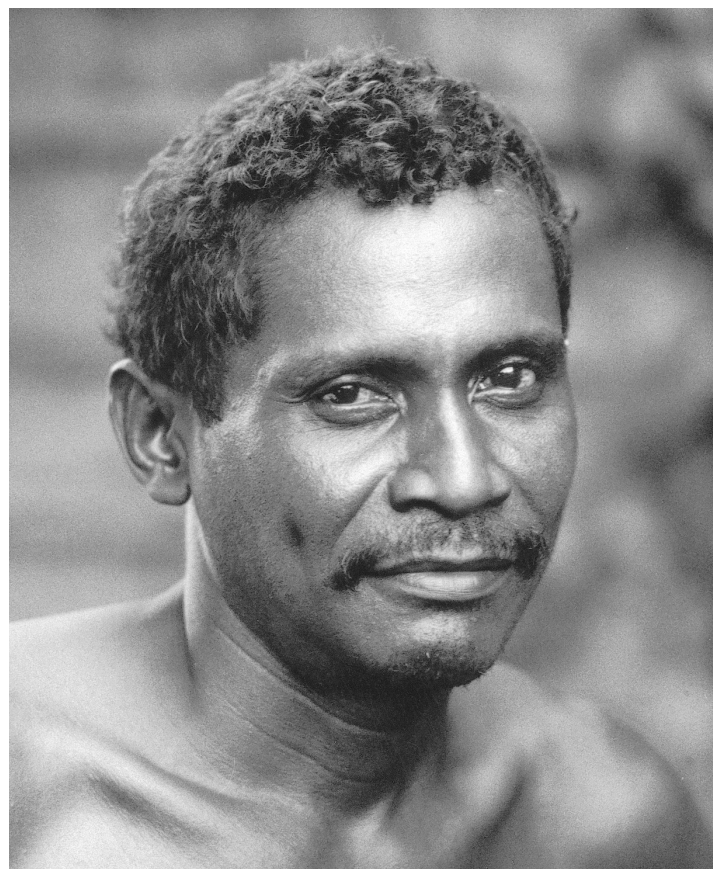

Collantes. afromixteca de la Costa, Vittorio D’Onofri, 1995

bueno añadir que esta relación no ha sido fácil, pues desde sus inicios, a ambas disciplinas les ha interesado, en sus ambiciones totalizadoras, dar cuenta del hombre y su transformación social.

El creciente interés entre los antropólogos por la historia y entre los historiadores por la antropología nos permite mirar con optimismo el trabajo del etnohistoriador, quien comparte con los historiadores el gusto por la búsqueda incansable de información de primera mano, de archivo; con los antropólogos el de los procesos locales, de los "eventos", y el afán de proponer modelos que sirvan para una mejor comprensión del pasado y utiliza todo cuanto le es útil en su investigación, lo que "no implica necesariamente desorden o falta de rigor científico", 5 sino la búsqueda insaciable de nuevos derroteros para explicar la organización de las sociedades indígenas, pues los resultados de la investigación etnohistórica no son

\footnotetext{
5 José Luis de Rojas, 1989, "Tendencias de la etnohistoria del México central”, en Revista de Indias, XLIX, 185, 195-204.
} 
diferentes de los estudios históricos. Lo que anima ahora es el interés por trabajar temas y problemas, es decir, los procesos que nos lleven a una mejor comprensión de la sociedad.

La segunda tiene que ver con la búsqueda, la creación y la ubicación de las fuentes, de los datos, de los "eventos" y el contexto social que los genera o suprime, y de la interpretación de nueva información, como la realizada a partir de los expedientes escritos en lenguas indígenas, con el fin de "comprender a la otra sociedad", de interpretar el "silencio documental", y del manejo de la tradición oral que hacen muchos individuos, grupos o pueblos para recrear su propia historia, como apuntan Raymond Fogelson y Frank Salomon. ${ }^{6}$

Por cierto, la búsqueda de nuevas fuentes de información se considera uno de los quehaceres más importantes y fructíferos para lograr la recuperación y revalorización del proceso histórico de los pueblos americanos. Es uno de los medios más indicados para llegar a romper el círculo vicioso de las fuentes generalizantes y de las visiones simplistas de sus seguidores. Es, ante todo, una táctica de investigación, un medio con el que se pretende recuperar la escamoteada realidad cotidiana de los diferentes grupos sociales, a través de información de primera mano y, sobre todo, en aquellos campos tradicionalmente omitidos. Y éste es un punto importante de aclarar: la búsqueda documental que nos hemos impuesto muchos de nosotros y que priva en algunos centros de trabajo como tarea esencial de la investigación etnohistórica no es indiscriminada; estamos explorando temas y problemas de importancia teórica que son esenciales para la recuperación de la "historia compleja de los grupos indios y campesinos". En este sentido, el trabajo de Matthew Restall busca mostrarnos la trayectoria de la "nueva filología", de una nueva escuela que pretende ser "teórica y metodológica", aunque en sus resultados "abarca sólo las publicaciones en lengua inglesa". Matthew apunta que,

\footnotetext{
${ }^{6}$ Raymond D. Fogelson, "La etnohistoria de eventos..." y Frank Salo-
} mon, "Una etnohistoria..., ambos artículos en este número. la nueva filología incluye a los investigadores dedicados a la etnohistoria de Mesoamérica durante el período colonial, cuyas aportaciones se basan en fuentes primarias en lenguas indígenas, subrayando un análisis filológico de sus fuentes y enfatizando la importancia crucial de las fuentes nativas para el conocimiento de las sociedades indígenas.

Y añade que:

sus dos principales contribuciones, no sólo a la etnohistoria colonial de Mesoamérica, sino a la historia colonial de América Latina, han sido el acercamiento a las fuentes primarias indígenas como el centro fundamental de la investigación etnohistórica, y la reorientación de la historia colonial hacia las perspectivas indígenas.

Sin embargo, ambas contribuciones, por cierto, han estado presentes desde hace muchos años en México. El interés por las fuentes indígenas escritas en nauatl ha llevado a la publicación y análisis de importantes documentos, esfuerzo que debemos, en sus inicios, principalmente a Paul Kirchhoff y Luis Reyes García. ${ }^{7}$ La documentación de archivo ganó, pues, terreno frente a las crónicas, y éstas fueron objeto de cuidadosos análisis.

La documentación de archivo es sin duda la más importante y específica y es la que ha permitido los mayores avances en los años recientes. Se trabajan todo tipo de acervos. Algunos proyectos de investigación se han propuesto, incluso, como uno de sus principales objetivos, la publicación de colecciones documentales. La diferencia que puede establecerse entre este esfuerzo reciente y el de los que los antecedieron (José F. Ramírez, Francisco

\footnotetext{
${ }^{7}$ Paul Kirchhoff, Lina Odena Güemes y Luis Reyes García, 1976, Historia Tolteca-Chichimeca, México, INAH, CISINAH, SEP. La Historia Tolteca-Chichimeca "es el sueño cumplido, aunque póstumo, de uno de los más grandes mesoamericanistas: Paul Kirchhoff. Es modelo de estudio histórico, de traducción y de edición facsimiliar”. Alfredo López Austin, 1986, "Diez años del CISINAH-CIESAS. El programa de etnohistoria”, en Anales 1984, 35-38, CIESAS, México. Luis Reyes García ha continuado con ese estilo de trabajo; muestra de ello son la paleografía, traducción, presentación y notas que realizó, junto con Andrés Martínez Baracs, de la obra de Juan Buenaventura Zapata y Mendoza, 1995, Historia cronológica de la noble ciudad de Tlaxcala, Universidad Autónoma de Tlaxcala, CIESAS, y la que publicó junto con Eustaquio Celestino Solís, Armando Valencia Ríos, Constantino Medina Lima y Gregorio Guerrero Díaz, 1996, Documentos nauas de la Ciudad de México del siglo XVI, Archivo General de la Nación, México, CIESAS.
} 
del Paso y Troncoso, Silvio Zavala), es que en la actualidad se trata de una búsqueda selectiva, que está orientada por el interés sobre determinadas temáticas y sobre áreas geográficas ricas desde el punto de vista de sus archivos.

Gracias a esta labor, la idea de una cultura homogénea, que poco o nada se había transformado, ha ido desapareciendo. Pero queda por advertir la preocupación que externó hace varios años Pedro Carrasco y que recogió muy atinadamente Briggitte Boehm en una reseña: "Los etnohistoriadores mexicanos han desenterrado un cúmulo de información potencialmente explosivo para la ciencia antropológica en general; es la hora en que los etnohistoriadores mexicanos midan, analicen e interpreten estos materiales, antes de que su ingenua voluntad de participar sus fuentes sea aprovechada por otros más listos y menos laboriosos que ellos"; 8 o como apunta atinadamente Romero Frizzi: "Sin un cuidadoso manejo de las fuentes históricas, sin nuevas preguntas que guíen nuestro camino por el bosque de los documentos, sin buenas técnicas de análisis, no hay buena etnohistoria"; y Fogelson, cuando señala que se trata de "construir nuevas hipótesis" y de "formular preguntas novedosas sobre las fuentes documentales". Es decir, la búsqueda especializada y la lectura crítica de "papeles" no son suficientes, importa analizar e interpretar para una mejor comprensión de las transformaciones que han ocurrido en la sociedad.

Es de esperar que con estos materiales podamos abordar algunos temas como el de la tecnología agrícola, o profundicemos de manera puntual sobre la organización indígena colonial y su funcionamiento a través, por ejemplo, de las actas del cabildo de Tlaxcala, que fueron traducidas y analizadas por Eustaquio Celestino, Armando Valencia y Constantino Medina; ${ }^{9}$ o de la vida cotidiana de

\footnotetext{
${ }^{8}$ Brigitte Boehm 1988, Relaciones, IX [34],primavera, 147-149. ${ }^{9}$ Actas de cabildo de Tlaxcala 1547-1567, paleografía, traducción e introducción de Eustaquio Celestino, Armando Valencia y Constantino Medina, 1985, Archivo General de la Nación, Instituto Tlaxcalteca de Cultura, CIESAS, México. Un año después salió a la luz la traducción de las actas al inglés de James Lockhart, Frances Berdan y Arthur J.O. Anderson, The Tlaxcalan actas. A Compendium of the Records of the $\mathrm{Ca}$ bildo of Tlaxcala (1545-1627), 1986, Salt Lake City, University of Utah Press.
}

los nobles indígenas a partir de la reciente obra de Teresa Rojas Rabiela, Elsa Leticia Rea López y Constantino Medina sobre los "testamentos indígenas novohispanos". 10

En el diálogo entre historiadores y antropólogos, entre el pasado y presente, debemos tomar en cuenta las sugerencias de Frank Salomon y Raymond Fogelson cuando apuntan que es necesario considerar "las tradiciones orales indígenas" en nuestras investigaciones, o al menos tener sensibilidad para entender la elaboración que hacen los propios campesinos de su devenir, pues ellos "crean una versión eficaz del pasado", de su pasado, donde "se nota que los marcos tomados de la historia oral, de los ritos modernos y de las preocupaciones pragmáticas dentro de la política influencian la selección entre las lecturas pausibles a primera vista". Sorprende la vitalidad que tienen las tradiciones, así como la cantidad de ancianos, que guardan, conservan y recrean celosamente la tradición oral, la memoria oral, la memoria colectiva de sus pueblos y que aún podemos entrevistar, pero también la población de todas las edades que participa en la renovación puntual de la historia y costumbres locales, como es el caso de León Modesto Rojas Alberco, que tan bien nos ejemplifica Frank Salomon. Sin embargo, es pertinente señalar algunas preguntas: ¿qué relaciones se van tejiendo entre una historia oficial y la de Rojas Alberco, consensada por el pueblo, y que apunta claramente a otra forma de significación de su pasado? ¿De qué forma coincide la historia de Rojas Alberco con las historias de los pueblos más o menos cercanos? ¿Cómo, por medio de qué mecanismos, esta historia llega a ser o constituirse en una tradición oral aceptada por los comuneros? La respuesta, por aventurar una, podría estar en que la identidad colectiva del grupo se funda en la elaboración de cierta historia, que deviene en mito de origen impregnada de magia religiosa. Aquí surge algo que el etnohistoriador no debe soslayar y que bien señala Romero Frizzi cuando apunta:

\footnotetext{
10 Teresa Rojas Rabiela, Elsa Leticia Rea López, Constantino Medina Lima, 1999-2000, Vidas y bienes olvidados. Testamentos indígenas novohispanos, 3 vols., col. Historias, Centro de Investigaciones y Estudios Superiores en Antropología Social, SEP-Conacyt, México.
} 
El conocimiento de la sociedad nativa y la lectura casi entre líneas de los documentos buscando las ideas indígenas y sus sentires implica pasos sutiles, difíciles de describir, trataré de esbozarlos. El primero y tal vez el más obvio es sencillamente conocer a los descendientes contemporáneos de aquellos pueblos de antaño. El trabajo de campo en la etnohistoria no es un paso evitable en el proceso de conocer, es central... Del presente y del conocimiento etnográfico debemos marchar cuidadosamente hacia el pasado [...] Otro paso más, evidentemente, es el estudio del idioma de las personas cuyo pasado queremos conocer, pensando que el idioma contiene no sólo el pensamiento indígena, sino su pensamiento en constante interacción con el mundo que lo rodea.

La vitalidad de la investigación etnohistórica se debe, pues, a dos razones; la primera, a la presencia de los herederos de las "civilizaciones indígenas" y a "la riqueza y diversidad de las fuentes documentales", tal como apunta Mathew Restall, sin olvidarnos, por supuesto, de la tradición oral. ${ }^{11}$

La tercera línea ofrece los resultados, libros, artículos y ensayos de quienes, desde la etnohistoria, han hecho propuestas novedosas, pues "se han esforzado por comprender a la otra sociedad".

Puedo señalar que las líneas de investigación que ha seguido la etnohistoria mexicana son esencialmente sobre la historia de los indios, de los campesinos y la evolución de los pueblos rurales; un buen ejemplo sería la Historia de los pueblos indígenas de México, que coordinan Teresa Rojas Rabiela y Mario Humberto Ruz. ${ }^{12} \mathrm{Su}$

\footnotetext{
${ }^{11}$ Jan Vansina en su clásico trabajo, La tradición oral (1967, Nueva Colección Labor, 22, Editorial Labor, Barcelona), basado en el trabajo de campo en África, señala la importancia de las tradiciones orales y discute la relación entre el método histórico y la tradición oral. Carlos Montemayor sugiere que demos una mirada a los trabajos sobre la tradición oral hecha por yugoslavos, rusos e indoeuropeos, "La cosmovisión de los pueblos indígenas actuales”, 2000, Desacatos, 5, invierno, 95-106.

12 Los coordinadores proponen que "una lectura distinta del pasado no es sólo necesidad académica; conlleva fundamentos políticos y culturales, puesto que la historia oficial, que se ha pretendido única, y la visión que los medios electrónicos e impresos difunden sobre la historia de los pueblos indios en la construcción del devenir nacional, se oculta o minimiza como si hubiesen dejado de existir en el momento mismo en que los europeos arribaron al continente o se les considera,
}

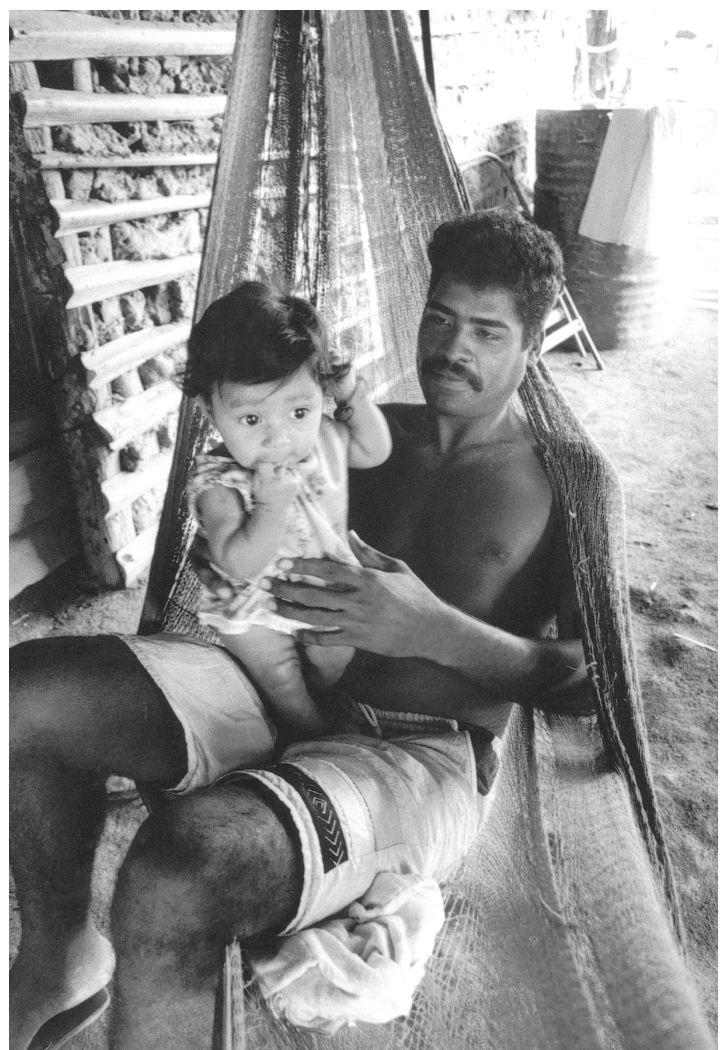

Collantes, afromixteca de la Costa, Vittorio D’Onofri, 1995

en el mejor de los casos, sólo en función de las acciones que éstos desplegaron; meros receptores de influencias, de 'cultura' y de civilización; telón de fondo de los afanes de los recién llegados y sus descendientes". Antropólogos e historiadores que han contribuido en esta historia son: Danièle Dehouve, 1994, Entre el caimán y el jaguar. Los pueblos indios de Guerrero, CIESAS, INI, México; Mario Humberto Ruz, 1994, Un rostro encubierto. Los indios del Tabasco colonial, CIESAS, INI, México; María de los Ángeles Romero Frizzi, El sol y la cruz. Los pueblos indios de Oaxaca colonial, 1996, CIESAS, INI, México; Jan De Vos, 1996, Vivir en frontera. La experiencia de los indios de Chiapas, CIESAS, INI, México; Carlos Manuel Valdés, 1995, La gente del mezquite. Los nómadas del noreste en la Colonia, CIESAS, INI, México; Martha Rodríguez, 1995, Historias de resistencia y exterminio. Los indios de Coahuila en el siglo XIX, CIESAS, INI, México; Evelyn Hu-DeHart, 1995, Adaptación y resistencia en el Yaquimi. Los yaquis durante la Colonia, CIESAS, INI, México; Cynthia Radding, 1995, Entre el desierto y la sierra. Las naciones o'idham y tegüima de Sonora, 1530-1840, CIESAS, INI, México; Héctor Cuauhtémoc Hernández Silva, 1996, Insurgencia y autonomía. Historia de los pueblos yaquis: 1821-1910, CIESAS, INI, México; Sergio Quezada, 1997, Los pies de la república. Los mayas peninsulares, 1550-1750, CIESAS, INI, México; Victoria Chenaut, 1995, Aquellos que vuelan. Los totonacos en el siglo XIX, CIESAS, INI, México; Antonio Escobar Ohmstede, 1998, De la costa a la sierra. Las Huastecas, 1750-1900, CIESAS, INI, México; Carlos González Herrera y Ricardo León García, 2000, Civilizar o exterminar. Tarahumaras y apaches en Chihuahua, siglo XIX, CIESAS, INI, México. 
quehacer ha estado relacionado con temas como el estado, el comercio, los tributos, la identidad indígena y campesina y el parentesco; precursores de estos temas fueron los antropólogos Ángel Palerm y Pedro Carrasco. El período colonial y la época prehispánica han sido, de hecho, la especialización más importante de los etnohistoriadores mexicanistas, y es en esa etapa donde han concentrado sus esfuerzos.

Sin embargo, nuevos campos y temas de investigación han surgido en estos últimos años, que me permiten hablar del surgimiento de nuevas propuestas, sin dejar de lado los trabajos clásicos, sobre todo de historiadores como François Chevalier, Charles Gibson y otros.

Se ha avanzado mucho respecto al estudio de la hacienda, sin embargo, aún no aparece la obra que emule a la de François Chevalier. ${ }^{13}$ Pero aún hacen falta más investigaciones, pues la formación y desarrollo de la hacienda está íntimamente ligado al proceso de cambio en la tenencia de la tierra indígena, sobre todo en el primer siglo colonial, tema que ha sido descuidado por los historiadores. La hacienda, foco de interés de muchos investigadores, dejó en la oscuridad a su contraparte, la tierra de los pueblos indios. El excelente trabajo de Hanns J. Prem, Milpa y hacienda, ${ }^{14}$ trata de mostrarnos la estructura agraria de la territorialidad indígena, los cambios que se sucedieron en el régimen de propiedad de la tierra y la formación de la territorialidad española. Nos sugiere, por otro lado, que el proceso de mercedación de tierras estuvo íntimamente ligado al de las reducciones o congregaciones de los pueblos indios (1594-1604). De esta manera y sin temor a equivocarnos, podemos señalar que las mercedes de tierras que se otorgaron a los españoles no sólo dependieron de su voracidad por las tierras, sino que estuvieron ligadas a la reestructuración de un nuevo espacio, más acorde con las necesidades del sistema colonial, en el cual, sin embargo, los indígenas lograron conservar sus tierras.

${ }^{13}$ François Chevalier, 1976, La formación de los latifundios en México. Tierra y sociedad en los siglos XVI y XVII, Fondo de Cultura Económica, México.

${ }^{14}$ Hanns Prem, 1988, Milpa y hacienda. Tenencia de la tierra indígena y española en la cuenca del alto Atoyac, Puebla, México (1520-1650), Fondo de Cultura Económica, Gobierno del Estado de Puebla, CIESAS, México.

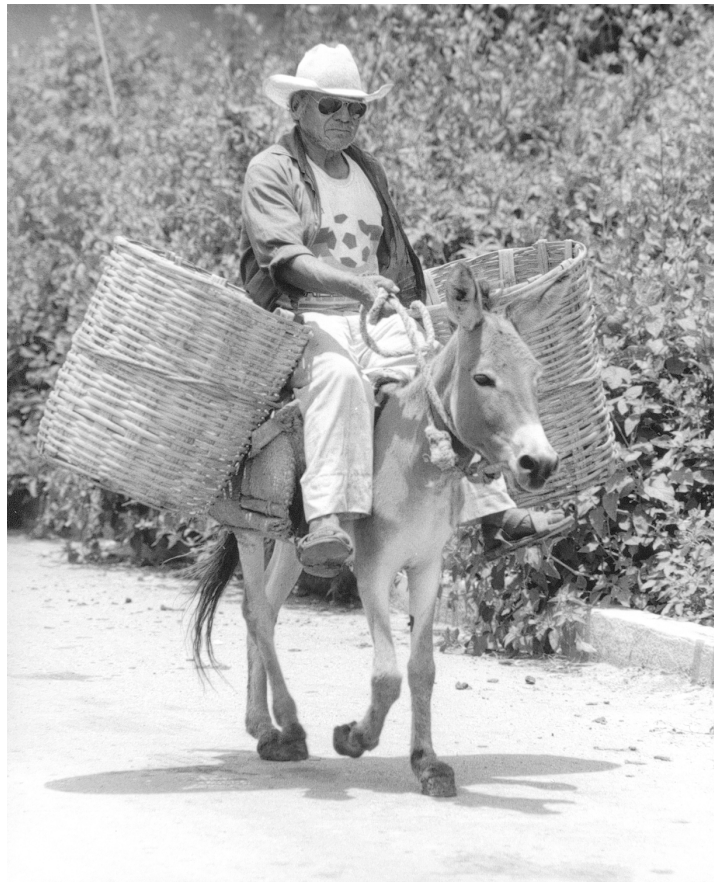

San Juan Teitipac, zapoteca del Valle, Vittorio D’Onofri, 1995

Por ello sería interesante comprobar que, a lo largo de la época colonial, la producción en los territorios indígenas, en términos no sólo cuantitativos, siguió siendo más importante que la de las haciendas. Sin embargo, aún persiste una gran laguna sobre el proceso de consolidación de la tenencia de la tierra y la territorialidad indígena a lo largo de la época colonial y de la formación de la territorialidad española, y aún más, esta ausencia sigue vigente en el siglo XIX. Sin embargo, a pesar de lo señalado, debo apuntar que el reciente trabajo de Hildeberto Martínez —Codiciaban la tierra - así como el anterior - Tepeaca en el siglo XVI-, nos proporcionan elementos para el análisis comparativo y regional. ${ }^{15}$

\footnotetext{
${ }^{15}$ Hildeberto Martínez, 1994, Codiciaban la tierra. El despojo agrario en los señoríos de Tecamachalco y Quecholac (Puebla, 1520-1650), CIESAS, México; y Tepeaca en el siglo XVI. Tenencia de la tierra y organización de un señorío, 1984, Ediciones de la Casa Chata, 21, CIESAS, México. Desde otra perspectiva, la del área andina, la obra de María Isabel Remy y Luis Miguel Glave, Estructura agraria y vida rural en una región andina. Ollantaytambo entre los siglos XVI-XIX, trata de mostrarnos la
} 
La monumental obra de Charles Gibson, Los aztecas..., ${ }^{16}$ aun cuando se ocupa de la imposición de las instituciones españolas a los indios, nos permite reconstruir la historia indígena del México central. Menos polémica que la obra de otros autores, nos ofrece una serie de temas donde abundan las descripciones acerca de la estructura social económica, política y agraria; permite el replanteamiento de muchos supuestos acerca de los pueblos indígenas del México colonial y nos brinda una compilación impresionante de información. Quien elaboró dos trabajos que son representativos del estilo gibsoniano de hacer historia fue William Taylor en sus obras Landlord and Peasant in Colonial Mexican y Embriaguez, homicidio y rebelión, donde nos presenta la manera creativa en cómo las comunidades indígenas lograron asimilar y conservar su identidad a pesar de las imposiciones del sistema colonial español. ${ }^{17}$ En este sentido, muchos trabajos y tesis de licenciatura, sobre todo de la Escuela Nacional de Antropología e Historia, han sido planeados alrededor de Los aztecas..., y desarrollan, para otras áreas, el esquema planteado por Gibson. Esto permite acercarnos de una manera comparativa al estudio de las etnias mesoamericanas durante la Colonia. ${ }^{18}$

Los trabajos que, desde una perspectiva antropológica, han llamado la atención por abordar temas nunca antes tratados por los historiadores, son los que realizó Pedro Carrasco alrededor de la familia, el parentesco, los linajes y los barrios. ${ }^{19}$ Las propuestas planteadas por

estructura agraria de las territorialidades indígenas, los cambios que se sucedieron en el régimen de propiedad de la tierra y la formación de la territorialidad española. Así, los trabajos de Martínez, Prem, Remy y Glave sugieren que sólo sobre la base de la reconstrucción del sistema de tenencia de la tierra es factible llegar a enunciados y proposiciones más minuciosos.

${ }^{16}$ Charles Gibson, 1980, Los aztecas bajo el dominio español (1519-1810), Siglo XXI Editores, col. América Nuestra, 15, México.

17 William B. Taylor, 1987, Embriaguez, homicidio y rebelión en las poblaciones coloniales mexicanas, Fondo de Cultura Económica, México. ${ }^{18}$ La influencia de Gibson llegó a los Andes con Karen Spalding, quien en su libro De indio a campesino (1974, Instituto de Estudios Peruanos, Lima), invita a realizar un obra paralela a la de Gibson para el mundo andino.

19 Para dar sólo un ejemplo de la extensa obra de Pedro Carrasco en estos temas: 1976, "Los linajes nobles del México antiguo", en Pedro Carrasco y Johanna Broda (coords.), Estratificación social en la Mesoamérica prehispánica, SEP-INAH, México, pp. 19-36; 1976, "La jerarquía
Carrasco no han tenido, sin embargo, la atención de los estudiosos, salvo algunas excepciones, como el reciente trabajo de Hildeberto Martínez. ${ }^{20}$ Sin embargo, para el área andina ésta ha sido una de las líneas más fructíferas gracias a la labor pionera de John V. Murra con sus Formaciones económicas y políticas del mundo andino y $\mathrm{La}$ organización económica del Estado inca, ${ }^{21}$ continuada por muchos historiadores y antropólogos, sin olvidar a María Rostworowski. ${ }^{22}$

Desde una perspectiva más agrícola, que busca explicar los efectos de la introducción de las plantas y técnicas agrícolas europeas y la modificación de la agricultura indígena prehispánica, se encuentra el trabajo de Teresa Rojas Rabiela y William T. Sanders, Historia de la agricultura. Epoca prehispánica y siglo XVI; el de Jesús Ruvalcaba, Agricultura india en Cempoala, Tepeapulco, Tulancinco (siglo XVI), y el de Carlos Paredes, La región de Atlixco, Huaquechula y Tochimilco. La sociedad y su agricultura durante el siglo XVI. ${ }^{23}$ Una nueva vertiente ligada a la tenencia de la tierra ha sido el estudio sobre el control del agua por los pueblos indígenas y la sociedad en general durante la Colonia; varias tesis de licenciatura y maestría dan muestra de ello. ${ }^{24}$

cívico-religiosa de las comunidades mesoamericanas: antecedentes prehispánicos y desarrollo colonial”, en Estudios de Cultura Náhuatl, 12, pp. 165-184; 1961, "El barrio y la regulación del matrimonio en un pueblo del Valle de México en el siglo XVI", en Revista Mexicana de Estudios Antropológicos, 17, pp. 7-26; 1974, "Sobre algunos términos de parentesco en el náhuatl clásico", en Estudios de Cultura Náhuatl, 6, pp. 149-166; 1974, "Sucesión y alianzas matrimoniales en la dinastía teotihuacana”, en Estudios de Cultura Náhuatl, 11, pp. 235-241.

${ }^{20}$ Hildeberto Martínez, 2000, "El calpulli. ¿Otra acepción de teccalli?”, en The Journal of Intercultural Studies, 27, pp. 194-208.

${ }^{21}$ John V. Murra, 1975, Formaciones económicas y politicas del mundo andino, Instituto de Estudios Peruanos, Lima; y 1978, La organización económica del Estado inca, Siglo XXI Editores, México.

22 Rafael Varón Gabai y Javier Flores Espinoza (eds.), 1997, Arqueología, antropología e historia en los Andes. Homenaje a María Rostworowski, Instituto de Estudios Peruanos, Banco Central de Reserva del Perú, Lima.

23 Teresa Rojas Rabiela y William T. Sanders, 1985, Historia de la agricultura. Época prehispánica-siglo XVI, 2 vols., Instituto Nacional de Antropología e Historia, col. Biblioteca del INAH, México; Jesús Ruvalcaba Mercado, 1985, Agricultura india en Cempoala, Tepeapulco y Tulancingo. Siglo XVI, Departamento del Distrito Federal-México, Unión de Ciudades Capitales Iberoamericanas, México; Carlos Paredes Martínez, La región de Atlixco, Huaquechula y Tochimico. La sociedad y su agricultura en el sigo XVI.

24 Un trabajo pionero sobre esta temática es el de Michael Mayer, 1997, El agua en el suroeste hispánico. Una historia social y legal, 1550-1850, 
Del diálogo entre la historia y la geografía han salido propuestas interesantes, como la obra de Bernardo García Martínez, Los pueblos de la Sierra, ${ }^{25}$ donde se analiza la formación, integración y fragmentación de los altepetl de la Sierra norte de Puebla en el sistema colonial. Para ello estudia no sólo las funciones políticas y administrativas de las instituciones coloniales, sino que realiza un análisis espacial o geográfico de los pueblos, donde encuentra sentido su integración y posterior fragmentación. El espacio, el medio físico — es decir, la geografía- adquiere otra dimensión. Los conceptos de región, espacio, altepetl, pueblo, se encuentran a lo largo de la obra y nos permiten visualizar un nueva manera de analizar la historia colonial. Esta prometedora línea ha recibido eco en la obra de René García Castro, Indios, territorio y poder... ${ }^{26}$ Un viejo tema como nuevas preguntas ha surgido con cierto ímpetu en los últimos años; me refiero a la preocupación creciente sobre el clima, los desastres, la deforestación, etcétera, y que se ha reunido bajo el título de historia ambiental. A partir del diálogo de historiadores y antropólogos con la naturaleza y el meElinor Melville, Plaga de ovejas, ${ }^{27}$ donde se han hecho interrogantes sobre los bosques, la desertificación, la desecación. ${ }^{28}$

Por último, considero que la obra de Nancy M. Farris, Maya society under Colonial rule. The collective enterprise of survival, representa el único gran esfuerzo por tratar en una forma total la historia de la sociedad indígena, en

CIESAS, Instituto Mexicano de Tecnología del Agua, col. Biblioteca del Agua, México.

${ }^{25}$ Bernardo García Martínez, 1987, Los pueblos de la Sierra. El poder y el espacio entre los indios del norte de Puebla hasta 1700, El Colegio de México, México.

${ }^{26}$ René García Castro, 1999, Indios, territorio y poder en la provincia Matlatzinca. La negociación del espacio politico de los pueblos otomianos, siglos XV-XVII, El Colegio Mexiquense, CIESAS, Instituto Nacional de Antropología e Historia, México.

27 Elinor G. K. Melville, 1999, Plaga de ovejas. Consecuencias ambientales de la conquista de México, Fondo de Cultura Económica, México. ${ }^{28}$ Una serie de artículos sobre este tema encontrarán en la compilación hecha por Bernardo García Martínez y Alba González Jácome, 1999, Estudios sobre historia y ambiente en América I: Argentina, Bolivia, México, Paraguay, El Colegio de México, Instituto Panamericano de Geografía e Historia, México.

su caso, la maya yucateca. Se ocupa fundamentalmente del proceso de cambio y asimilación de la población indígena a la estructura colonial. Nos explica que a través del análisis de la continuidad funcional y estructural de la familia, del linaje, del territorio, de la religión, de las instituciones españolas como el cabildo y las cofradías, que fueron recreadas por los indígenas, se puede explicar la supervivencia de la población indígena. La sobrevivencia, así como la cohesión social, son vistas como empresas colectivas y van a explicar a lo largo de la época colonial no sólo el proceso de fragmentación de los pueblos, sino también su centralización, que permitió la adaptación más que la desintegración y donde los mecanismos de reciprocidad y redistribución siempre están en juego. Es decir, el cambio y la sobrevivencia cultural se dieron por la creativa adaptación de la población indígena a la estructura colonial. La obra de Nancy M. Farris es un trabajo histórico desde una perspectiva antropológica. Nos ofrece una rica y abundante información sobre la funcionalidad interna de la sociedad indígena. Muestra que el conservadurismo de los historiadores sobre el uso de teorías o conceptos antropológicos se ha roto y esto nos abre nuevos caminos para realizar futuros trabajos sobre la historia de los grupos étnicos mesoamericanos. En este sentido, la obra de Farris nos ofrece un nuevo modelo de interpretación y nos sugiere contar con una formación interdisciplinaria para realizar investigaciones de esta magnitud.

Todos los trabajos a los que he hecho referencia no son sino propuestas e intentos dispersos que esperan ser integrados en un marco teórico y una problemática más amplia, casi total.

Para concluir debo señalar dos observaciones más: la primera, sobre el provincianismo de los etnohistoriadores de toda América: somos especialistas de un tema y de un pueblo; y la segunda, que deberíamos buscar la manera de comparar el desarrollo de esta joven disciplina con lo que se ha hecho en la etnohistoria africana, andina, etcétera. La etnohistoria debe dejar de ser una disciplina difícil, heterodoxa y bastarda, para ser querida y reconocida, sobre todo desde la antropología. 